\title{
EFFECT OF DIFFERENT MICROBIAL AGENTS ON CORN STALK COMPOSTING
}

\author{
ChANG, H. Y. ${ }^{1,2}-$ LU, S. F. ${ }^{1,2}-$ HUANG, Z. Y. ${ }^{1,2}-$ LIU, Y. X. ${ }^{1,2}-$ WANG, T. Y. ${ }^{1,2}-$ WANG, C. Y. ${ }^{1,2^{*}}-$ \\ LIU, S. X. ${ }^{1,2 *}$ \\ ${ }^{1}$ College of Resources and Environmental, Jilin Agricultural University, Xincheng Street \\ No.2888, Changchun 130118, People's Republic of China \\ ${ }^{2}$ Key Laboratory of Soil Resources Sustainable Utilization for Jilin Province Commodity Grain \\ Bases, Changchun 130118, Jilin Province, China \\ ${ }^{*}$ Corresponding authors \\ e-mail: wangchengyu2001@163.com; phone:+86-1894-6690-848; \\ e-mail: liushuxia69@163.com; phone: +86-1554-3133-987 \\ (Received $4^{\text {th }}$ Feb 2020; accepted $6^{\text {th }}$ May 2020)
}

\begin{abstract}
This study explored the effects of different microbial agents on corn stalk composting to enable the development of agents suitable for composting corn stalks in cold regions of northern China. Four different microbial treatment groups were established: CK (straw), L (straw $+1 \%$ low-temperature bacteria), $\mathrm{M}$ (straw $+1 \%$ normal-temperature bacteria), $\mathrm{LM}$ (straw $+0.5 \%$ low-temperature bacteria + $0.5 \%$ normal-temperature bacteria), and tests were repeated 3 times for each group. The results show that the temperature of the heap reached $50^{\circ} \mathrm{C}$ on the second day of the $\mathrm{L}$ and $\mathrm{LM}$ treatments and reached $50^{\circ} \mathrm{C}$ on the sixth day of M. CK did not reach $50^{\circ} \mathrm{C}$ during the entire composting cycle. During the composting process, the seed germination index, the degradation rate of total nitrogen, the total potassium, the total phosphorus, the cellulose, and the hemicellulose degradation rates increased; In contrast, the water content, conductivity, organic carbon and $\mathrm{C} / \mathrm{N}$ showed a downward trend. The humic acid and fulvic acid contents in each treatment showed a downward trend, while the humic acid and HA/FA increased compared to CK. The conclusion of this experiment provides a theoretical basis for achieving the rapid degradation of straw in the cold regions of northern China.
\end{abstract}

Keywords: low-temperature bacteria, corn straw, compost, maturity, North China

\section{Introduction}

Corn stalk is a rich natural organic resource and can be used as a fertilizer source in agricultural production (Wang, 2018). At present, the world's straw resources are substantial and widely distributed, but the utilization rate is not high (Mulumba et al., 2008; Lou et al., 2011). Straw returning is one of the main ways to utilize straw resources. It is beneficial to the renewal of soil humus, the maintenance of soil organic matter balance and the improvement of soil quality and can contribute to fertility, protect the environment, increase the crop yield and is an important measure for promoting the sustainable development of agriculture (Hachicha et al., 2012; Hu et al., 2016). However, due to the influence of climate in the cold regions of northern China, the slow decomposition of straw after being returned to the field affects the planting and the cropping of the next year's crops. Further, this slow decomposition also allows some pests to survive in the soil for a long time, which can cause serious damage to crop growth (Gong et al., 2018). Therefore, accelerating the decomposition of straw is important. The application of microbial agents is an effective measure for achieving the rapid degradation of straw (Gao et al., 2014). Microbial agents can effectively break down straw into a large number of elements such as the nitrogen, phosphorus and 
potassium required by crops and trace elements such as calcium, magnesium, manganese and molybdenum, which can improve the physical and chemical properties of soil, improve soil organic matter, enhance soil aeration, protect fertilizer and water retention function, and stimulate crop growth and development (Zhou et al., 2018). Additionally, composting is an effective way to quickly dispose of livestock manure and agricultural waste. The heat generated during composting can kill viruses and weed seeds while decomposing the organic matter into stable humic substances that can be used as organic fertilizers (Yan et al., 2018). Therefore, this study conducted a simple composting test on straw by adding low-temperature bacteria, normal-temperature bacteria and low-temperature and normaltemperature mixed bacteria to study the dynamic changes occurring in the various maturity indexes during the composting process, thus providing feasible management methods for straw wastes in northern areas.

\section{Materials and Methods}

\section{Composting materials and devices}

The corn stalks were collected in the experimental field of Jilin Agricultural University and pulverized to approximately $5 \mathrm{~cm}$ with a pulverizer. The basic properties are shown in Table 1. The low-temperature bacterial agent is composed of lowtemperature bacteria preserved in the laboratory, including 14 (Yellow bacillus), 49 (Chain mildew genera) and NX5 (Section coli); the normal-temperature bacterium is Y2 (Short-wave pseudomonas); and the effective viable number of bacteria is $\geq 108 \mathrm{cfu} / \mathrm{g}$.

Table 1. Basic properties of corn straw

\begin{tabular}{c|c|c|c|c}
\hline $\begin{array}{c}\text { Organic carbon } \\
\left(\mathrm{g} \cdot \mathrm{kg}^{-1}\right)\end{array}$ & $\begin{array}{c}\text { Total nitrogen } \\
\left(\mathrm{g} \cdot \mathrm{kg}^{-1}\right)\end{array}$ & $\begin{array}{c}\text { Total phosphorus } \\
\left(\mathrm{g} \cdot \mathrm{kg}^{-1}\right)\end{array}$ & $\begin{array}{c}\text { Total potassium } \\
\left(\mathrm{g} \cdot \mathrm{kg}^{-1}\right)\end{array}$ & $\begin{array}{c}\text { Moisture content } \\
(\%)\end{array}$ \\
\hline 512.27 & 8.42 & 0.67 & 8.31 & 9.85 \\
\hline
\end{tabular}

\section{Composting device}

A soil trough with dimensions of $80 \times 50 \times 40$ was excavated on the outdoor test site, and a layer of plastic cloth was placed on the bottom to prevent water from penetrating the ground. The pulverized straw was covered with plastic cloth to prevent water loss and reduce the effects of rainy day.

\section{Compost design}

Four treatments were established: CK (straw), L (straw $+1 \%$ low-temperature bacteria), $\mathrm{M}$ (straw $+1 \%$ normal-temperature bacteria), $\mathrm{LM}$ (straw $+0.5 \%$ low-temperature bacteria $+0.5 \%$ normal-temperature bacteria), and each treatment had 3 replications. Each treatment received $15 \mathrm{~kg}$ of corn stover, $1 \%$ of the microbial agent, and added groundwater to adjust the straw water content to approximately $65 \%$, with the $\mathrm{C} / \mathrm{N}$ being adjusted with urea to approximately 25 . The mixture was uniformly mixed and placed in the composting device, where it was piled into a small hill shape so that the straw was approximately $20 \mathrm{~cm}$ higher than the composting device. The experiment was conducted at the outdoor breeding ground of Jilin Agricultural University. Composting began on April 20, 2019, and the piles were piled up and sampled every 5 days. The composting time lasted for 40 days. 


\section{Sample collection}

The heaps were piled up and sampled every 5 days. The samples from the upper, middle and lower parts were collected and mixed thoroughly. Then, approximately $200 \mathrm{~g}$ of the composting material was placed in two Ziploc bags: one for water content, $\mathrm{pH}$ and conductivity (EC); one for the seed germination index (GI) and other indicators; and the third one for natural air drying for organic carbon, total nitrogen, total phosphorus, total potassium, cellulose degradation rate, hemicellulose degradation rate and humus content.

\section{Determination methods}

\section{Determination of temperature}

The temperature was measured at the center of the pile at 8:30 am and 16:30 pm every day, and the average of the two measured temperatures was taken as the stack temperature of the day; the ambient temperature was also measured.

\section{Determination of water content}

Samples were taken, and $10.00 \mathrm{~g}$ of each were dried to a constant weight at $105^{\circ} \mathrm{C}$.

\section{Extraction}

Extracts were obtained by using a water: fresh sample ratio of $10: 1 \mathrm{~mL} / \mathrm{g}$ on a shaker for $2 \mathrm{~h}$; the mixture was then filtered, and the filtrate served as the extract for the determination of the $\mathrm{pH}$, conductivity (EC) and seed germination index.

The $\mathrm{pH}$ was measured by using a $\mathrm{pH}$ meter, and the conductivity (EC) was measured with a TM-03 waterproof conductivity meter.

\section{Determination of the seed germination index $(G I)$}

An appropriately sized filter paper was placed in a high-temperature sterilization dish with a diameter of $90 \mathrm{~mm}$. Ten soybean seeds were evenly spaced on the paper, and $10 \mathrm{~mL}$ of the extract was added to the culture dish. Treated water was used as a blank control. The dish was placed in a constant temperature incubator at $25^{\circ} \mathrm{C}$ and cultured in the dark for $48 \mathrm{~h}$ to determine the seed germination rate and root length. The seed germination index $(\mathrm{GI})=$ (sample germination rate $\times$ sample root length $) /($ control germination rate $\times$ control root length $) \times 100 \%$.

The determination of organic carbon, total nitrogen, total phosphorus and total potassium was carried out according to the method for determining organic fertilizerrelated indicators following the national standard (Cao et al., 2014).

Cellulose and hemicellulose degradation rates were determined by the Van Soest (Wang et al., 2016) washing method.

\section{Determination of the components of the humus}

The extraction of the components of the humus is based on the humus composition modification method (Dou et al., 2007). The carbon contents of the extracted humus, humic acid (HA) and fulvic acid (FA) were determined by external heating while using potassium dichromate. 


\section{The data processing}

Excel 2016 and SPSS 24.0 were used for data collation and statistical analysis.

\section{Results}

\section{Stack temperature}

As can be seen from Fig. 1, the ambient temperature varies from $11.0^{\circ} \mathrm{C}$ to $27.5^{\circ} \mathrm{C}$ during the composting period, and the ambient temperature in the early composting period is less than $25^{\circ} \mathrm{C}$. On the first day of composting, the ambient temperature was $21.5^{\circ} \mathrm{C}$, and the temperatures of the treated $\mathrm{CK}, \mathrm{L}, \mathrm{M}$, and $\mathrm{LM}$ stacks were $21.7^{\circ} \mathrm{C}$, $20.7^{\circ} \mathrm{C}, 22.0^{\circ} \mathrm{C}$, and $21.6^{\circ} \mathrm{C}$, respectively. After treatment, the temperature of $\mathrm{L}$ and $\mathrm{LM}$ increases rapidly, reaching $50^{\circ} \mathrm{C}$ or more on the next day and staying above $50^{\circ} \mathrm{C}$ for 10 days. The maximum temperature of the treatment $\mathrm{M}$ was $60.6^{\circ} \mathrm{C}$, and the maximum temperature of $\mathrm{LM}$ was $61.8^{\circ} \mathrm{C}$, with a temperature of more than $60^{\circ} \mathrm{C}$ being maintained for 3 days. The treatment $\mathrm{M}$ reached $50^{\circ} \mathrm{C}$ on the sixth day, where it stayed for 6 days. The CK, which lacked the added microbial agent, did not reach $50^{\circ} \mathrm{C}$ during the entire composting process. After the high-temperature period, the temperature of the reactor began to decrease. After 20 days, the temperature of each treatment reactor was basically maintained at approximately $30^{\circ} \mathrm{C}$. The heap temperature, except for that of $\mathrm{CK}$, was maintained at $55^{\circ} \mathrm{C}$ for more than 3 days or at $50^{\circ} \mathrm{C}$ for more than $5-7$ days, which is sufficient to kill harmful substances.

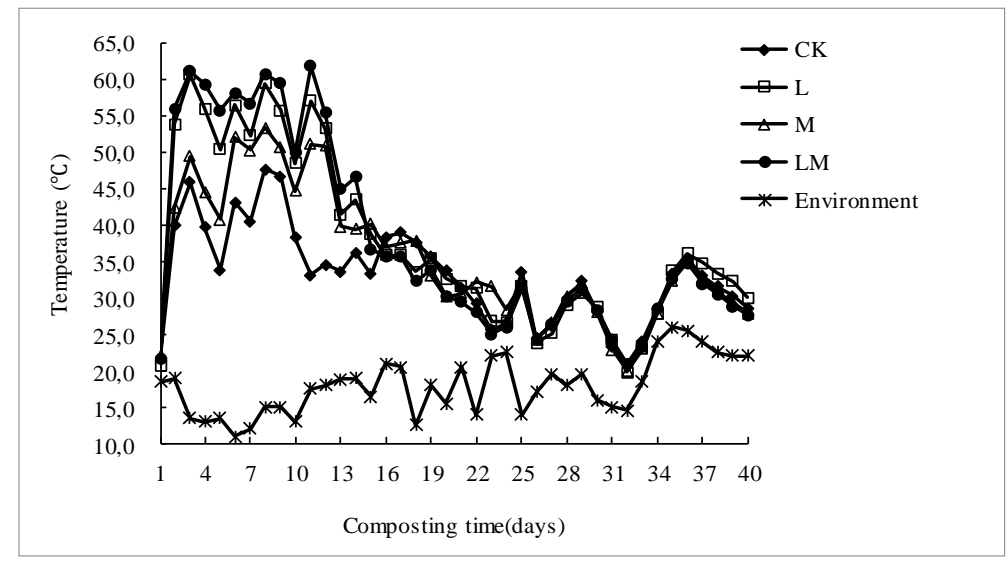

Figure 1. Change of compost temperature during composting

\section{Water content of the heap}

As shown in Fig. 2, the water content of the pile gradually decreased with the composting time. The water content when composting was initiated was approximately $65 \%$. At 5 days, the water content of each treatment was significantly reduced. The water contents of CK, L, M and LM decreased by $7.51 \%, 10.44 \%, 9.11 \%$ and $11.39 \%$, respectively. During the entire composting cycle, the moisture content of LM was the largest, CK was the smallest, and the treatment $\mathrm{L}$ and $\mathrm{M}$ were between the two. At the end of composting, the water contents of CK, L, M and LM were $43.51 \%, 38.19 \%$, $39.21 \%$ and $36.35 \%$, respectively, and these values were $22.03 \%, 26.77 \%, 25.79 \%$ and $28.92 \%$ lower than the initial values. 


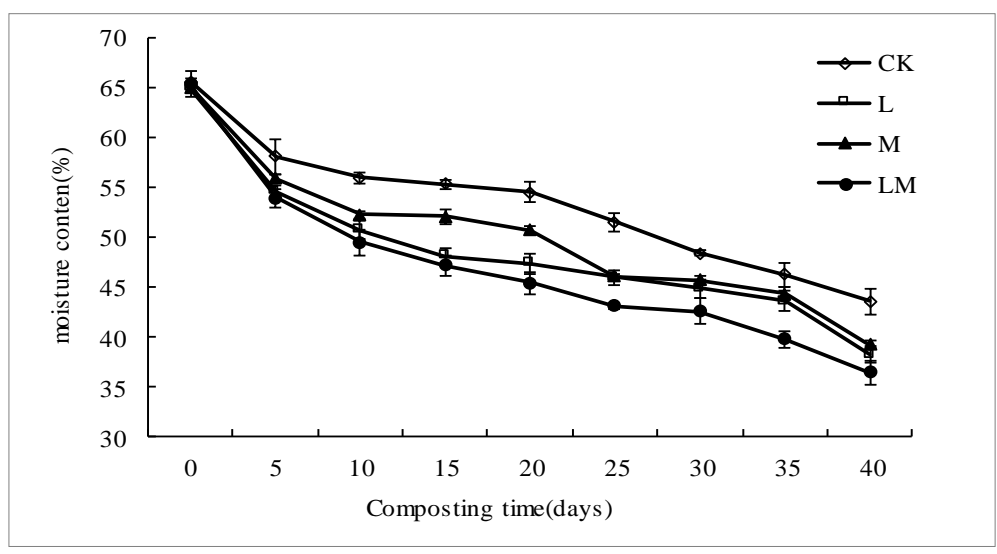

Figure 2. Change in moisture content during composting (The error bars displayed in the figure is the positive and negative deviation of the standard deviation of data in different sampling days for each treatment)

\section{pH and conductivity (EC)}

As shown in Fig. 3, the $\mathrm{pH}$ values of the $\mathrm{CK}, \mathrm{L}, \mathrm{M}$, and LM treatments before composting were $7.54,7.61,7.61$, and 7.59 , respectively. The $\mathrm{pH}$ of the treated LM increased rapidly, reaching a maximum of 8.42 on the 10th day, whereas the $\mathrm{pH}$ of the treated L, M and CK peaked on days 15, 20 and 20, respectively, with values of 8.61, 8.50 and 8.36. Afterward, the $\mathrm{pH}$ of each treatment decreased to a different extent. At the end of composting, the $\mathrm{pH}$ values of the CK, L, M and LM treatments were 8.16, $8.33,8.35$ and 8.11 , respectively.

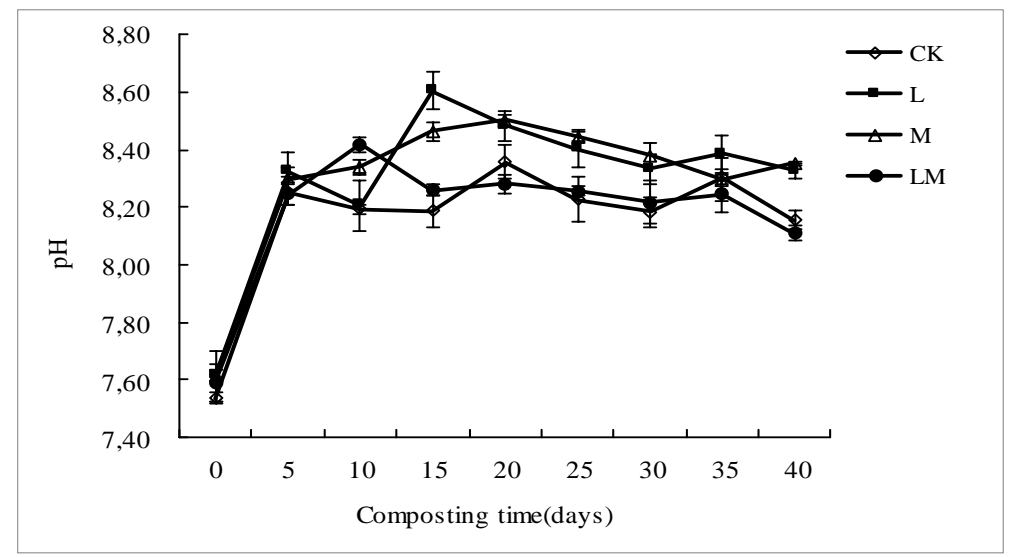

Figure 3. Changes in pH during composting (The error bars displayed in the figure is the positive and negative deviation of the standard deviation of data in different sampling days for each treatment)

As shown in Fig. 4, with the change in composting time, the conductivity of each treatment shows a general trend of decreasing first and then slowly increasing before stabilizing. At 60 days, the conductivity of the LM treatment was the smallest, CK was the highest, and $\mathrm{L}$ and $\mathrm{M}$ were between the two. Over the entire composting period, the conductivity change between treatments was not particularly significant but was less than $3000 \mu \mathrm{s} / \mathrm{cm}$. 


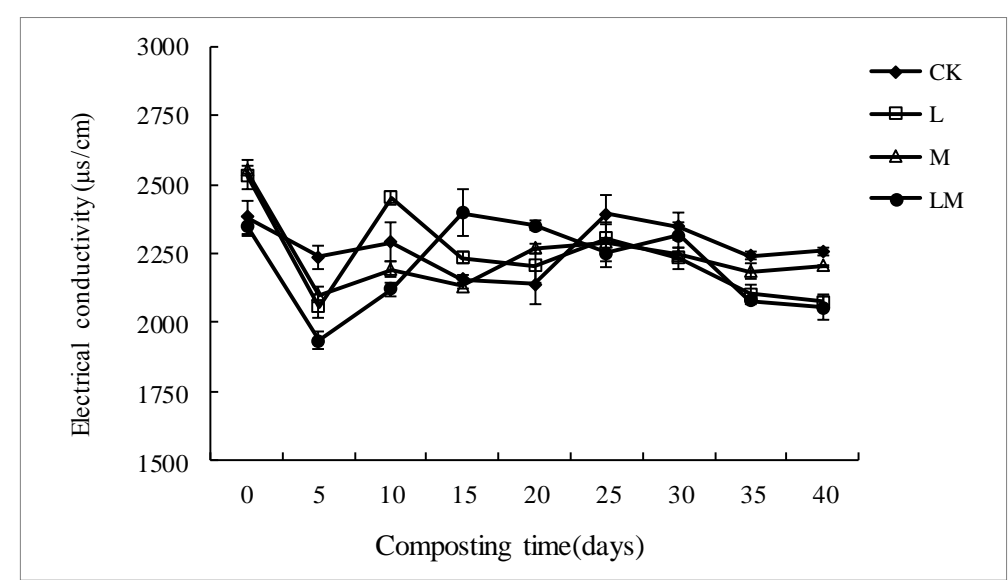

Figure 4. Changes in electrical conductivity during composting (The error bars displayed in the figure is the positive and negative deviation of the standard deviation of data in different sampling days for each treatment)

\section{Seed Germination Index (GI)}

As shown in Fig. 5, the seed germination index gradually increases with the composting time, but on the fifth day, the seed germination index of each treatment is reduced, which may be due to the generation of harmful substances in the heap. After the fifth day, the seed germination index of each treatment increased significantly, with that of the LM treatment increasing most obviously, CK increasing the least, and L and $\mathrm{M}$ increasing with values between the two. On the 15th day of treatment, for LM, the seed germination index reached $80 \%$. For $\mathrm{L}$ and $\mathrm{M}$, it reached $80 \%$ on the 20 th day, and for $\mathrm{CK}$, it reached $80 \%$ on the 25th day. At the end of composting, the germination index of the L, M and LM seeds treated with added microbial agents was $100 \%$, and for CK, it was $95.27 \%$, which indicated that the compost had reached maturity. This result may be obtained because the corn stalk itself contains less toxicity, and composting can increase the nutrients of the heap, thus providing sufficient seed germination and nutrients.

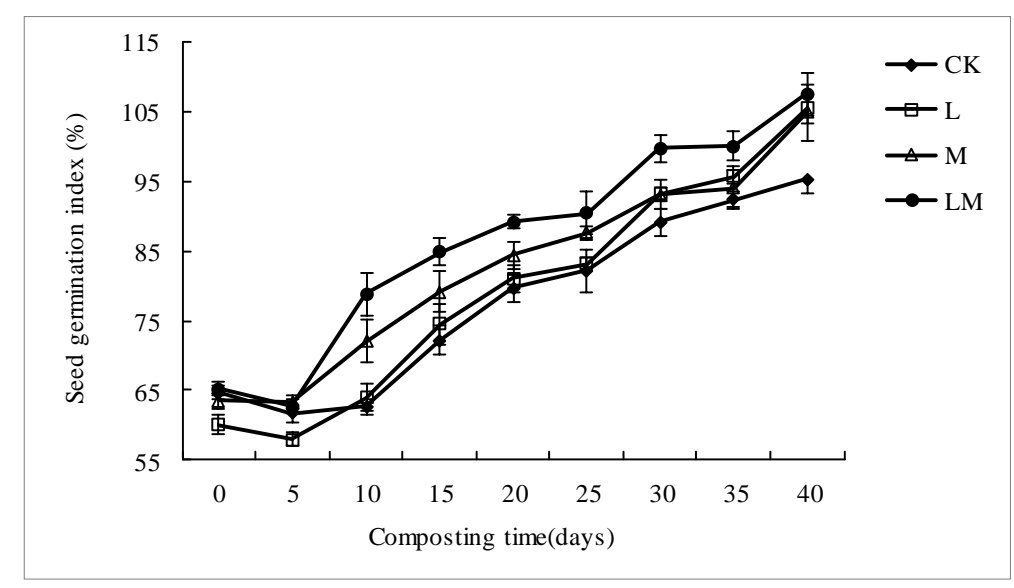

Figure 5. Changes in the seed germination index during the composting process (The error bars displayed in the figure is the positive and negative deviation of the standard deviation of data in different sampling days for each treatment) 


\section{Total nitrogen, organic carbon and $\mathrm{C} / \mathrm{N}$}

As shown in Fig. 6, during the composting process, the total nitrogen content generally increased, and the total nitrogen following the addition of the microbial agent was significantly higher than that of CK. The initial total nitrogen was approximately $2 \%$. At the end of composting, the total nitrogen contents of $\mathrm{L}, \mathrm{M}$ and $\mathrm{LM}$ were $2.35 \%$, $2.38 \%$ and $2.56 \%$, respectively, and were $0.14 \%, 0.17 \%$ and $0.35 \%$ higher than that $\mathrm{CK}$. The microbial agent had a significant increasing effect on the total nitrogen during composting. On the 10th day, a decline occurred that was probably due to the high microbial activity at this stage, which led to an increase in temperature and, as a result, a large release of $\mathrm{NH}_{3}$, thus decreasing the nitrogen content; then the nitrogen content gradually increased gradually, probably due to composting. With the maturation of the organic matter, the decomposition of the minerals and the organic carbon content continued to decline, thus promoting the enrichment of total nitrogen (Li et al., 2015).

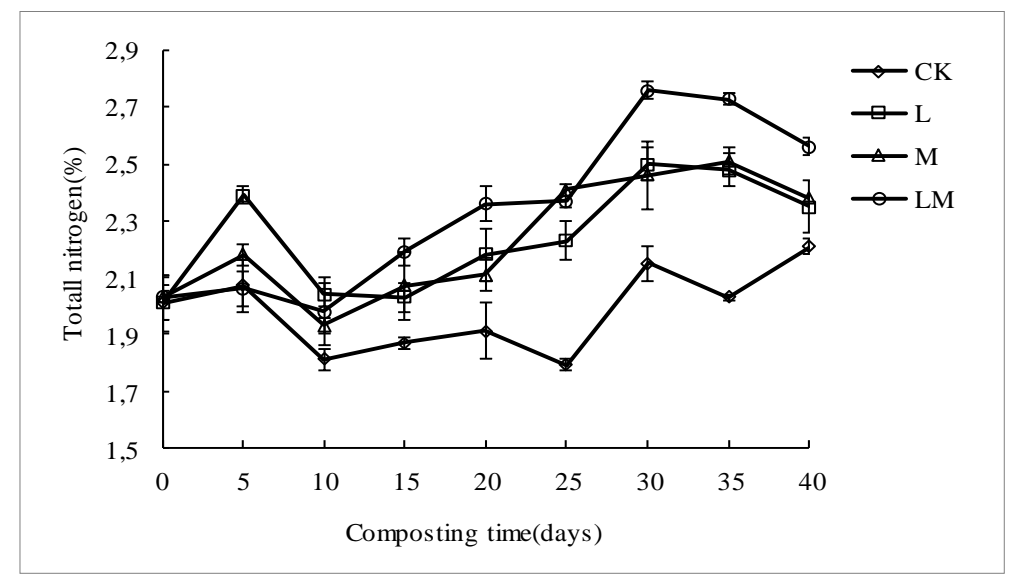

Figure 6. Changes in total nitrogen during the composting process (The error bars displayed in the figure is the positive and negative deviation of the standard deviation of data in different sampling days for each treatment)

As shown in Fig. 7, the organic carbon content is approximately 52\% at the beginning of composting and then decreases with the increase in composting time. The LM treatment showed a rapid decrease in the organic carbon content, whereas the CK showed a slow decrease, with $\mathrm{L}$ and $\mathrm{M}$ falling in between the two. In the first 20 days, the decline in the organic carbon in each treatment was greater, but this decline slowed and basically stabilized after 20 days. This pattern may be due to the strong energy consumption of the microorganisms in the early composting period, which caused the loss of carbon sources. At the end of composting, the organic carbon contents of CK, L, $\mathrm{M}$ and LM were $33.67 \%, 31.95 \%, 32.77 \%$ and $29.88 \%$, respectively. The organic carbon content of the LM treatment was significantly $(\mathrm{p}<0.05)$ lower than in the other treatments.

The initial $\mathrm{C} / \mathrm{N}$ range of composting is 25-30 (Zhang et al., 2015). As shown in Fig. 8, the C/N values of CK, L, M and LM at the initial composting are 26.24, 26.13, 25.78 and 25.98, respectively, which is especially suitable for microbial survival. However, as the composting test progressed, the $\mathrm{C} / \mathrm{N}$ of each treatment gradually decreased and finally stabilized. This pattern occurred because the microorganisms in the composting process need to consume a large amount of carbon sources to gradually 
reduce the organic carbon, whereas the relative content of the total nitrogen is increased, which means the $\mathrm{C} / \mathrm{N}$ is lowered. At the end of composting, the $\mathrm{C} / \mathrm{N}$ of the $\mathrm{CK}, \mathrm{L}, \mathrm{M}$, and LM treatments decreased to 15.24, 13.60, 13.77 and 11.67, respectively, with all being lower than 20 .

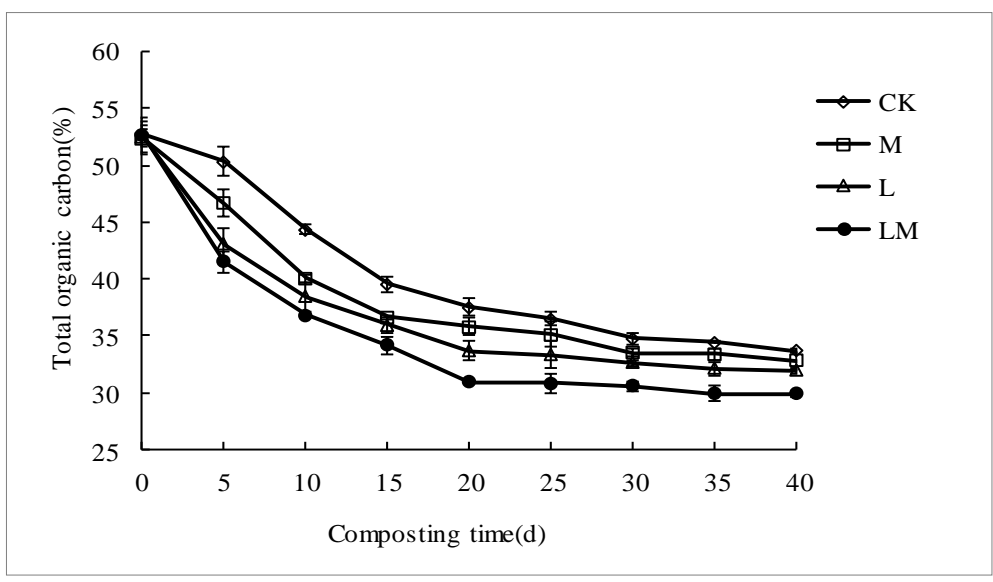

Figure 7. Changes in organic carbon during the composting (The error bars displayed in the figure is the positive and negative deviation of the standard deviation of data in different sampling days for each treatment)

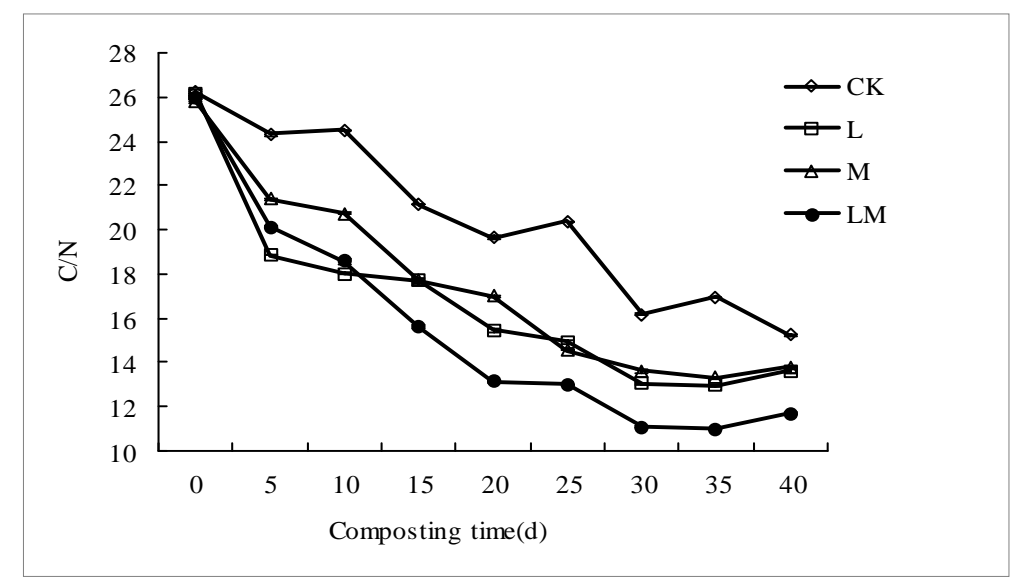

Figure 8. Changes of C/N during composting

\section{Total potassium and total phosphorus}

As shown in Fig. 9, the total potassium content of each treatment showed an increasing trend at the beginning of composting, and after 20 days, different trends began to appear. Treatments $\mathrm{L}$ and $\mathrm{M}$ reached the highest values at the end of composting with values of $15.18 \mathrm{~g} / \mathrm{kg}$ and $14.94 \mathrm{~g} / \mathrm{kg}$, respectively, whereas the highest values for LM and CK appeared on days 35 and 30 with values of $14.27 \mathrm{~g} / \mathrm{kg}$ and $14.41 \mathrm{~g} / \mathrm{kg}$. For the entire composting process, the total potassium content of the added microbial agents was higher than that of CK, indicating that the addition of microbial agents can promote the increase in the total potassium content. 


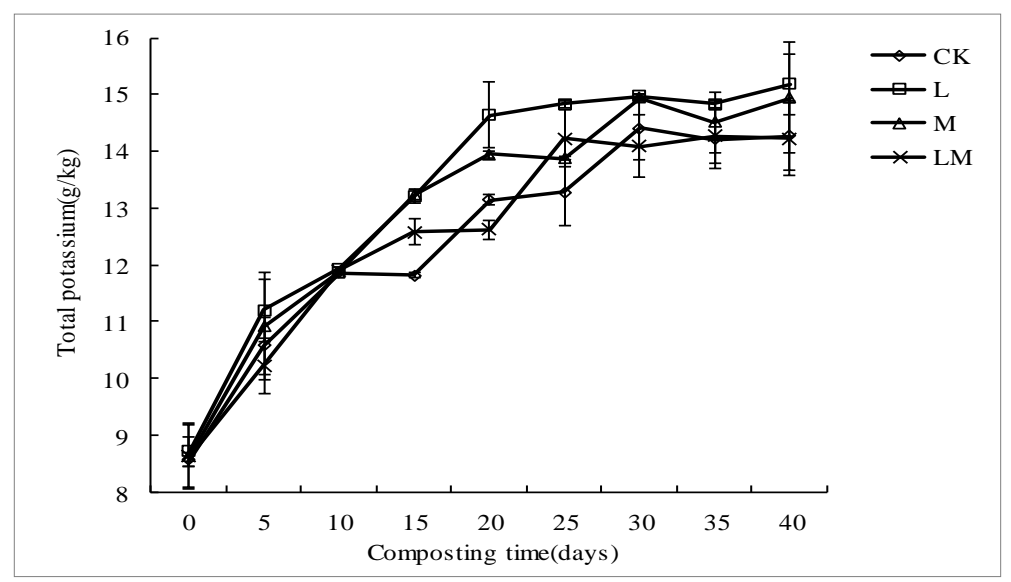

Figure 9. Change in the total potassium during the composting process (The error bars displayed in the figure is the positive and negative deviation of the standard deviation of data in different sampling days for each treatment)

As shown in Fig. 10, the total phosphorus content of each treatment gradually increased with the increase in the composting time. At 40 days of composting, the total phosphorus contents of CK, L, M and LM were $1.81 \mathrm{~g} / \mathrm{kg}, 1.88 \mathrm{~g} / \mathrm{kg}, 1.92 \mathrm{~g} / \mathrm{kg}$ and $2.11 \mathrm{~g} / \mathrm{kg}$, respectively. In contrast, the composting increased by 1.41 times, 1.37 times, 1.37 times and 1.81 times, respectively. The total phosphorus content observed over the entire composting process was as follows: $\mathrm{LM}>\mathrm{M}>\mathrm{L}>\mathrm{CK}$. As indicated, the low-temperature and normal-temperature mixed bacterial treatment had the best effect.

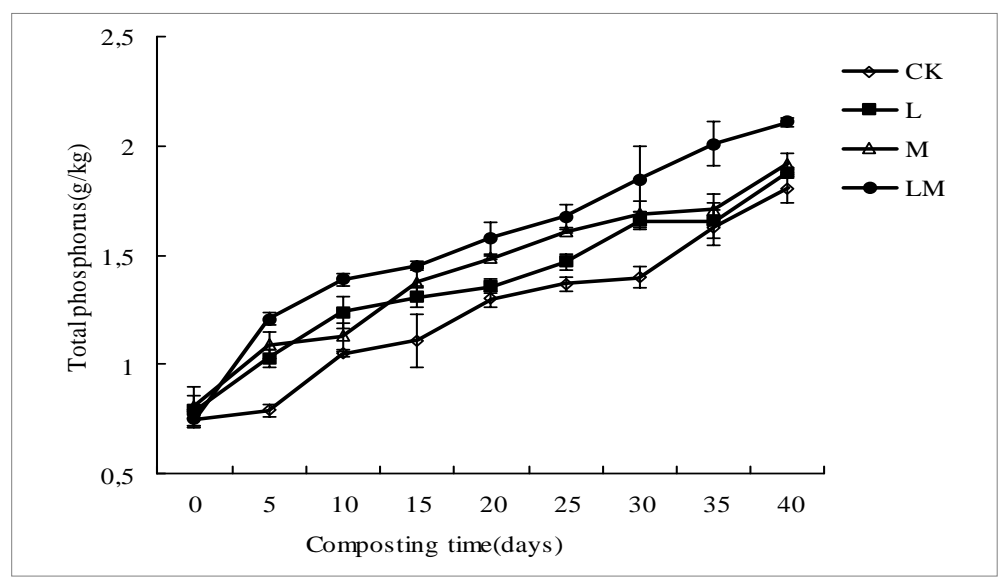

Figure 10. Change in the total phosphorus during the composting process (The error bars displayed in the figure is the positive and negative deviation of the standard deviation of data in different sampling days for each treatment)

\section{Degradation rate of cellulose and hemicellulose}

The main components of corn stalks include cellulose, hemicellulose, and lignin, which are difficult to decompose under natural conditions, and microorganisms provide the best means of degradation. As shown in Fig. 11, in the composting process, hemicellulose is decomposed by continuous consumption due to the vigorous activity of the microorganisms, so the degradation rate of the hemicellulose is continuously 
increased. However, the degradation rate of hemicellulose treated with added bacteria was significantly higher than that of CK, and the degradation rate of LM was always the greatest, with $\mathrm{L}$ and $\mathrm{M}$ being in between the two. At the end of composting, the hemicellulose degradation rates of CK, L, M and LM were $25.65 \%, 31.22 \%, 33.33 \%$ and $37.52 \%$, respectively, indicating that the addition of microbial treatment can significantly reduce the hemicellulose content, especially when inoculated at low or optimal temperatures.

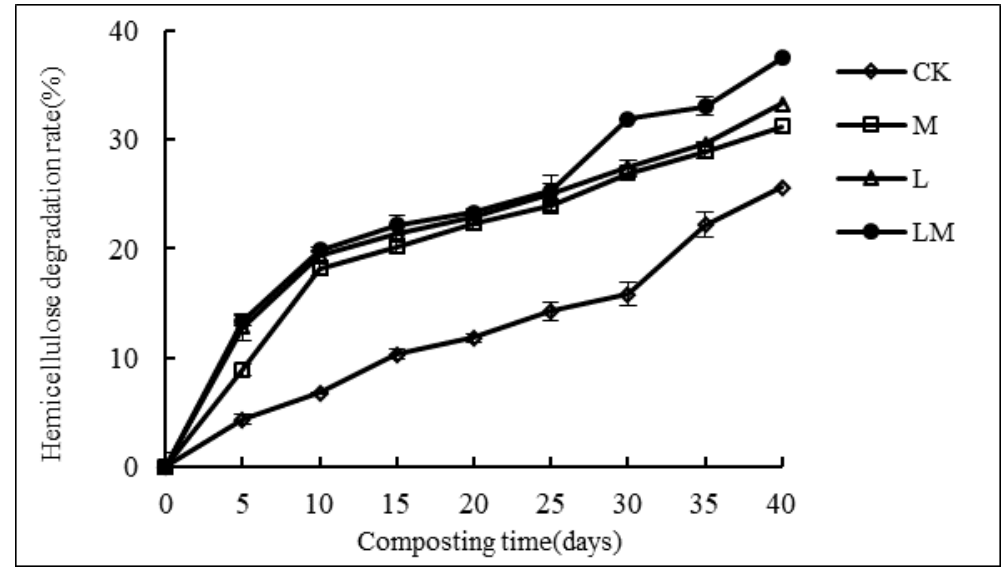

Figure 11. Changes in the degradation rate of the hemicellulose during the composting process (The error bars displayed in the figure is the positive and negative deviation of the standard deviation of data in different sampling days for each treatment)

The rate of degradation of cellulose was somewhat slower than that of the hemicellulose. As shown in Fig. 12, the cellulose degradation rates of CK, L, M and LM were $4.15 \%, 5.21 \%, 6.81 \%$ and $6.87 \%$, respectively, at 5 days of composting, and they were $23.05 \%, 25.18 \%, 28.71 \%$ and $32.15 \%$, respectively, at 40 days. The degradation rate of cellulose treated with added bacteria was significantly higher than that of CK. The degradation rate of cellulose in the whole composting process was as follows: $\mathrm{LM}>\mathrm{L}>\mathrm{M}>\mathrm{CK}$, which was consistent with the trend for changes in the hemicellulose degradation rate and indicates that the addition of microbial agents could promote the decomposition of cellulose and hemicellulose.

\section{Changes in humus composition}

As shown in Table 2, the humus, fulvic acid, humic acid and HA/FA were basically the same as before composting, and the difference was not significant $(\mathrm{p}<0.05)$; when composted for 60 days, humus and fulvic acid showed a downward trend, whereas the humic acid and HA/FA showed an increasing trend. The humic and fulvic acids of CK (72.55 and 37.06) and $M(79.82$ and 16.74) were significantly higher $(p<0.05)$ than those of L (53.04 and 12.21) and LM (63.31 and 12.90); compared with CK, in the treatments with added bacteria, the humic acid content of the treatments showed a significant increase $(\mathrm{p}<0.05)$. The order of HA/FA for the treatments was $\mathrm{LM}>\mathrm{M}>\mathrm{L}>\mathrm{CK}$, and the humus quality of the added bacteria was better than that of $\mathrm{CK}$. The humus contents of L and LM were lower, probably because the temperature of the heap was higher than that of $\mathrm{M}$ and $\mathrm{CK}$ during the composting process. Such an 
increase in temperature may lead to the more rapid decomposition rate of organic materials and to a lesser degree of humification.

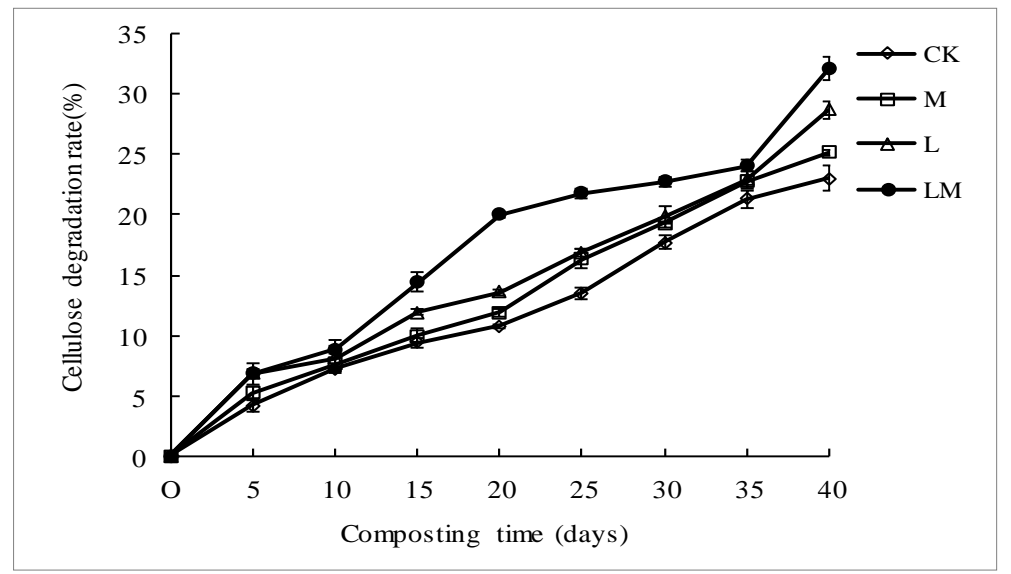

Figure 12. The change in the cellulose degradation rate during composting process (The error bars displayed in the figure is the positive and negative deviation of the standard deviation of data in different sampling days for each treatment)

Table 2. Changes in humus composition at the beginning and end of composting

\begin{tabular}{c|c|c|c|c|c}
\hline $\begin{array}{c}\text { Time } \\
(\mathrm{d})\end{array}$ & Treatment & $\begin{array}{c}\text { Humus } \\
(\mathrm{g} / \mathrm{kg})\end{array}$ & $\begin{array}{c}\text { Fulvic acid } \\
(\mathrm{g} / \mathrm{kg})\end{array}$ & $\begin{array}{c}\text { Humic acid } \\
(\mathrm{g} / \mathrm{kg})\end{array}$ & HA/FA \\
\hline 0 & CK & $90.99 \pm 0.10 \mathrm{a}$ & $61.44 \pm 0.92 \mathrm{a}$ & $29.55 \pm 1.91 \mathrm{a}$ & $0.48 \pm 0.04 \mathrm{a}$ \\
& L & $92.40 \pm 1.45 \mathrm{a}$ & $63.29 \pm 0.83 \mathrm{a}$ & $29.11 \pm 1.81 \mathrm{a}$ & $0.46 \pm 0.03 \mathrm{a}$ \\
& M & $92.49 \pm 0.41 \mathrm{a}$ & $61.38 \pm 2.64 \mathrm{a}$ & $31.11 \pm 3.03 \mathrm{a}$ & $0.49 \pm 0.07 \mathrm{a}$ \\
& LM & $91.30 \pm 5.51 \mathrm{a}$ & $63.81 \pm 3.52 \mathrm{a}$ & $27.50 \pm 2.02 \mathrm{a}$ & $0.43 \pm 0.01 \mathrm{a}$ \\
40 & CK & $72.55 \pm 0.68 \mathrm{a}$ & $37.06 \pm 0.42 \mathrm{a}$ & $35.49 \pm 1.09 \mathrm{~d}$ & $0.96 \pm 0.04 \mathrm{c}$ \\
& L & $53.04 \pm 2.55 \mathrm{c}$ & $12.21 \pm 0.16 \mathrm{c}$ & $40.83 \pm 2.42 \mathrm{c}$ & $3.34 \pm 0.16 \mathrm{~b}$ \\
& M & $79.82 \pm 6.70 \mathrm{a}$ & $16.74 \pm 0.68 \mathrm{~b}$ & $63.08 \pm 6.06 \mathrm{a}$ & $3.64 \pm 0.32 \mathrm{a}$ \\
& LM & $63.31 \pm 2.82 \mathrm{~b}$ & $12.90 \pm 0.76 \mathrm{c}$ & $50.41 \pm 2.08 \mathrm{~b}$ & $3.91 \pm 0.09 \mathrm{a}$ \\
\hline
\end{tabular}

The data in the table were $\overline{\mathrm{X}} \pm \mathrm{SD}$, different lowercase letters in the same column indicated significant difference $(P<0.05)$

\section{Discussion}

Composting is one of the means by which agricultural waste can be effectively utilized (Chen et al., 2015), and microbes play a leading role in the whole process of composting; thus, the addition of exogenous microorganisms is beneficial to accelerate the composting process (Wang et al., 2005). Composting studies on livestock manure, agricultural waste, and sludge have shown that the addition of microbial agents can increase the rate of decomposition and demonstrate the feasibility of adding exogenous agents (Lu et al., 2010; Gou et al., 2017). In this study, different microbial inoculants were added to the simple compost of corn stover, and the results showed that the temperature progression of the added bacteria treatment was accelerated, the high temperature period was prolonged, the seed germination index, total nitrogen, total potassium, total phosphorus, cellulose degradation rate, hemicellulose degradation rate, humic acid and HA/FA increased; however, the water content, conductivity, organic 
carbon, $\mathrm{C} / \mathrm{N}$, humus and fulvic acid decreased, shortening the maturity time and increasing the maturity effect.

Temperature is an important indicator of composting, which can reflect the degradation of organic components and affect the composting effect (Luo et al., 2013): the higher the temperature is, the more likely the death of any pathogens (González et al., 2015). In this study, the temperature of the corn stalk heap reached $50^{\circ} \mathrm{C}$, whereas in other studies that only used straw and cow dung or pig manure and other mixed composting, the temperatures reached $50^{\circ} \mathrm{C}$ or more. During the entire composting process in a study on fresh pig manure and wheat straw compost, the temperature did not reach $60^{\circ} \mathrm{C}$ (Ma et al., 2018). The current study shows that the addition of microbial agents can increase the temperature of the heap and quickly start and prolong the high temperature period, especially as observed with the LM treatment; these results are consistent with the results of Gou et al. (2017). An increase in temperature causes the water to evaporate, which affects the water content of the heap. Most studies have shown that, at the end of composting, the water content of the heap is less than $30 \%$ (Feng et al., 2013; Li et al., 2014), and at the end of the composting, the water content of each treatment is greater than $30 \%$, which may occur because part of the heap is buried in the soil and all of the heap is covered with a plastic sheet with a small vent, thus resulting in undisturbed water dispersion.

The increase in $\mathrm{pH}$ is due to the decomposition of proteins and amino acids during composting to produce ammonia, which increases the $\mathrm{pH}$ (Jiang et al., 2015). The $\mathrm{pH}$ reduction is due to the formation and nitrification of low molecular weight fats (Zorpas et al., 2008). The final $\mathrm{pH}$ of the test is less than 9, which meets the compost maturity standard (Debertoldi et al., 1983). Conductivity (EC) is an important indicator for use when measuring the compostability of materials. The conductivity of each treatment at the end of composting was less than $2500 \mu \mathrm{s} / \mathrm{cm}$, so it meets the requirements of compost maturity (Sheng et al., 2017) and will not affect the normal growth of plants. Some studies have suggested that when GI $>50 \%$, compost is basically harmless to plant growth and development and reaches basic maturity, whereas when GI>80\%, compost can be considered fully decomposed (Zucconi et al., 1981). In all the treatments in this study, the seed germination index was more than 50\% during the whole period of composting. This result may be obtained because the corn stalk itself contains less toxicity, and composting can increase the nutrients of the heap, thus providing sufficient seed germination and nutrients.

Composting can increase the total nitrogen, total potassium and total phosphorus content of organic matter, especially the addition of microbial agents, which is consistent with the results of Jia et al. (2011) and Gou et al. (2017). The reduction in the organic carbon in corn stalks is caused by the respiration of microorganisms, which causes the carbon source in the straw to be released in the form of $\mathrm{CO} 2$. The greater the number of microorganisms, the stronger the activity is and the greater the consumption of the carbon sources; thus, the organic carbon decreases more rapidly (Yang et al., 2013), $\mathrm{C} / \mathrm{N}$ is an important indicator to measure the degree of compost maturity. Generally, when $\mathrm{C} / \mathrm{N}$ is $15-20$, the compost has reached the maturity standard (Shi, 2010). At the end of composting, the $\mathrm{C} / \mathrm{N}$ of each treatment was less than 20 , so the decomposing effect was achieved. In comparison, the $\mathrm{C} / \mathrm{N}$ ratio reported by Wei et al. (2007) and for other domestic waste composts is 12.95 at 63 days, but most of the research on compost has reported a $\mathrm{C} / \mathrm{N}$ greater than 15 (Lao et al., 2015), which may be related to the initial adjustment of the $\mathrm{C} / \mathrm{N}$ ratio during composting. 
The addition of microbial compost is beneficial to the degradation of cellulose and hemicellulose, which is consistent with the results of Gou et al. (2015). This may be because, after the addition of the microbial agent, the enzyme produced can hydrolyze the cellulose and hemicellulose in the straw, thereby destroying the complex structure of the lignocellulose and promoting the rapid degradation of the straw. The composition, content and quality of humus in the compost can be used as important parameters for compost quality and maturity (Bremanis et al., 2013). The compost in this study showed a downward trend in the humus and fulvic acid, whereas the humic acid and HA/FA showed an increasing trend, which is consistent with the results of Chen et al. (2007) and Liu et al. (2018). Thus indicating that compost is beneficial to the transformation of organic matter to humus and to its stabilization.

\section{Conclusion}

The results of this study show that, compared with $\mathrm{CK}$, the treatments receiving the added microbial agents showed the rapid initiation of a high temperature period that was prolonged and showed beneficial changes in the seed germination index, total nitrogen, total potassium, total phosphorus, cellulose degradation rate, and hemicellulose degradation rate. The carbon content of HA and the HA/FA showed an increasing trend, whereas the water content, conductivity, organic carbon, $\mathrm{C} / \mathrm{N}$, humus and eucalyptus carbon content of the heap showed a downward trend with the addition of the lowtemperature bacteria + normal-temperature bacteria. The LM treatment showed the best effect, not only shortening the maturity cycle but also increasing the compost quality, which provides a theoretical basis for straw composting in areas with low temperatures.

\section{Implications for conservation}

This study explored the effects of different microbial agents on corn stalk composting to enable the development of microbial agents suitable for composting corn stalks in cold regions of northern China. Microbial agents can effectively breakdown straw into a large number of elements such as the nitrogen, phosphorus and potassium required by crops and trace elements such as calcium, magnesium, manganese and molybdenum, which can improve the physical and chemical properties of the soil, improve the soil organic matter, enhance soil aeration, protect fertilizer and water retention function, and stimulate crop growth and development. Additionally, composting is an effective way to quickly dispose of livestock manure and agricultural waste. The heat generated during composting process can break down organic matter into stable humus, which can be used as organic fertilizer. Therefore, this study conducted a simple composting test on straw by adding low-temperature bacteria, normal-temperature bacteria and low-temperature and normal-temperature mixed bacteria to study the dynamic changes occurring in the various maturity indexes during the composting process, thus providing feasible utilization measures for straw wastes in northern areas.

The results of this study show that, compared with $\mathrm{CK}$, the treatments receiving the added microbial agents showed the rapid initiation of a high temperature period that was prolonged and showed beneficial changes in the seed germination index, total nitrogen, total potassium, total phosphorus, cellulose degradation rate, and hemicellulose degradation rate. The carbon content of HA and the HA/FA showed an increasing trend, whereas the water content, conductivity, organic carbon, $\mathrm{C} / \mathrm{N}$, humus and eucalyptus 
carbon content of the heap showed a downward trend with the addition of the low-temperature bacteria + normal-temperature bacteria. The LM treatment showed the best effect, not only shortening the maturity cycle but also increasing the compost quality, which provides a theoretical basis for straw composting in areas with low temperatures.

Acknowledgements. We thank Yanan Li from Jilin University for her help in technical, and we are grateful to Yangsheng Wu, Yan Du, Jinxiu Li, Rong Cui, Xinyu Zhang and Qiuping Feng for their heip with sample extraction. Morover, we thank two anonymous reviwers for their comments on an earlier draft of this manuscript.

Author Contributions. Hongyan Chang, Shuifeng Lu, Ziyuan Huang, Yuxin Liu, Tianye Wang, Chengyu Wang and Shuxia Liu conceived the study. Hongyan Chang, Shuifeng Lu, Ziyuan Huang and Yuxin Liu performed the experiments. Hongyan Chang, Shuifeng Lu, Chengyu Wang and Tianye Wang wrote the manuscript. All authors reviewed the manuscript and agree with its contents.

Data Availability. The data used in this study is available from the corresponding author upon request.

Declaration of Conflicting Interests. The author(s) declared no potential conflicts of interest with respect to the research, authorship, and/or publication of this article.

Funding. The author(s) disclosed receipt of the following finacial support for the research, authorship, and/or pubilcation of this ariticle: This work is a contribution of the Jilin Province Science and Technology Development Plan (20160307006NY), National Key Research and Development Programme (2017YFD0300405-4), Natural Science Foundation of Jilin Province, China (20170101077JC).

Ethical approval. This article does not contain any studies with human participants or animals performed by any of the authors. The article is an original paper, is not under consideration by another journal, and has not been published previously. All authors read and approved the final manuscript.

\section{REFERENCES}

[1] Bremanis, G., Klavinš, M., Purmalis, O., Ziemelis, R., Malecka, S. (2013): Peat humic substances and earthworm biohumus extracts for agricultural applications. - Proceedings of the Latvian Academy of Sciences 67(3): 236-241.

[2] Cao, X. Y., Li, J. P., Yan, W. D. (2014): Distribution characteristics and coupling relationship of soil organic carbon and nitrogen, phosphorus and potassium in Chinese fir forests of different age groups. - The soil on notification 45(5): 1137-1143.

[3] Chen, G. Y., Wang, D. H., Wu, Y., Li, J. F., Liu, C. H., Xiang, Q. B. (2007): Dynamic changes of organic matter during defoliation composting. - Journal of South China Agricultural University 28(2): 1-4.

[4] Chen, M., Xu, P., Zeng, G. M., Yang, C. P., Huang, D. L., Zhang, J. H. (2015): Bioremediation of soils contaminated with polycyclic aromatic hydrocarbons, petroleum, pesticides, chlorophenols and heavy metals by composting: Applications, microbes and future research needs. - Biotechnology Advances 33(6): 745-755.

[5] Debertoldi, M., Vallini, G., Pera, K. A. (1983): The biology of composting: A review. Waste Management \& Research 1(1): 157-176.

[6] Dou, S., Yu, S. Q., Zhang, J. J. (2007): Effect of CO2 Concentration on Soil Humus Formation during Decomposition of Corn Stalk. - Journal of Soil Science 44(3): 458-466.

[7] Feng, Z., Li, J., Zhang, G. B., Li, W. L., Jia, H. Y., Liu, Z. F., Yu, J. H. (2013): Effect of different microbial agents on aerobic composting of corn stover. - Chinese vegetables $1(6 x): 82-87$. 
[8] Gao, Y. H., Gou, C. L., Wang, Y. Q., Wang, W., Zhao, H. X., Lou, Y. J. (2014): Study on the Effect of Low Temperature Compound Bacteria on Cow Manure Composting Fermentation. - Journal of Environmental Science 34(12): 3166-3170.

[9] Gong, J. J., Hu, H. X., Zhu, C. X., Tang, M. M., Xia, X. (2018): A Summary of the Effects of Straw Returning on Farmland Ecological Environment. - Jiangsu Agricultural Science 46(23): 44-48.

[10] González, I., Robledo-Mahón, T., Silva-Castro, G. A., Rodríguez-Calvo, A., Gutiérrez, M. C., Martín, M. Á., Chica, A. F., Calvo, C. (2015): Evolution of the composting process with semi-permeable film technology at industrial scale. - Journal of Cleaner Production 115: 245-254.

[11] Gou, C. L., Wang, Y. Q., Wang, W., Zhao, H. X., Lou, Y. J., Gao, Y. H. (2015): Screening and Identification of Low Temperature Cellulose Degrading Fungi from Two Changbai Mountain Areas and Optimization of Its Enzyme Production Conditions. Journal of Sun Yat-sen University (Natural Science Edition) 54(5): 115-121.

[12] Gou, C., Wang, Y., Zhang, X., Lou, Y., Gao, Y. (2017): Inoculation with a psychrotrophic-thermophilic complex microbial agent accelerates onset and promotes maturity of dairy manure-rice straw composting under cold climate conditions. Bioresource Technology 243: 339-346.

[13] Hachicha, R., Rekik, O., Hachicha, S., Ferchichi, M., Woodward, S., Moncef, N., Cegarra, J., Mechichi, T. (2012): Co-composting of spent coffee ground with olive mill wastewater sludge and poultry manure and effect of Trametes versicolor inoculation on the compost maturity. - Chemosphere 88(6): 677-682.

[14] Hu, C., Chen, Y. F., Qiao, Y., Liu, D. H., Zhang, S. T., Li, S. L. (2016): Improvement effect of straw returning with decomposing agent on low-yield yellow muddy field. Journal of Plant Nutrition and Fertilizer 22(1): 59-66.

[15] Jia, C. J., Zhang, Y. X., Du, W. C., Wang, D. G., Shi, T., Li, Y. K., Niu, Z. Y. (2011): Effect of microbial inoculation on the composting effect of pig manure. - Journal of Animal Ecology 32(5): 73-76.

[16] Jiang, J. S., Liu, X. L., Huang, Y. M., Huang, H. (2015): Inoculation with nitrogen turnover bacterial agent appropriately increasing nitrogen and promoting maturity in pig manure composting. - Waste Management 39: 78-85.

[17] Lao, D. K., Zhang, L. L., Li, Y. B., Du, Y., Han, H., Li, J. (2015): Effects of microbial straw decomposing agents with different inoculum on composting effect of vegetable byproducts. - Journal of Environmental Engineering 9(6): 2979-2985.

[18] Li, J., Yu, J. H., Feng, Z., Jie, J. M., Jie, X., Jiang, L., Zhang, J. (2014): Effect of different microbial agents on aerobic composting of cow manure. - Arid area resources and environment 28(2): 109-113.

[19] Li, Y., Li, W. (2015): Nitrogen transformations and losses during composting of sewage sludge with acidified sawdust in a laboratory reactor. - Waste Manage Res 33(2): 139145 .

[20] Liu, Y. Y., Xu, Z., Chen, Z. J., Tang, L. (2018): Effect of exogenous phosphorus phosphogypsum on carbon content and humus quality of compost. - Journal of Agricultural Environmental Science 37(11): 2483-2490.

[21] Lou, Y., Xu, M., Wang, W., Sun, X., Zhao, K. (2011): Return rate of straw residue affects soil organic c sequestration by chemical fertilization. - Soil and Tillage Research 113(1): 70-73.

[22] Lu, B. L., Wang, W. L., Li, J., Ma, Z. M. (2010): Effect of adding wheat straw on the composting process of pig manure at high temperature compost. - Journal of Environmental Engineering 4(4): 926-930.

[23] Luo, Y. M., Xu, D. G., Li, G. X. (2013): Effect of superphosphate as additive on nitrogen and carbon losses during pig manure composting. - Applied Mechanics and Materials 295-298: 1675-1679. 
[24] Ma, S. S., Sun, X. X., Fang, C., He, X. Q., Han, L. J., Huang, G. Q. (2018): Exploring the mechanisms of decreased methane during pig manure and wheat straw aerobic composting covered with a semi-permeable membrane. - Waste Management 78: 393400.

[25] Mulumba, L. N., Lal, R. (2008): Mulching effects on selected soil physical properties. Soil \& Tillage Research 98(1): 106-111.

[26] Sheng, D. C., Ao, J. H., Zhou, W. L., Chen, D. W., Huang, Y., Huang, Z. R., Li, Q. W., Jiang, Y. (2017): Effect of Different Organic Materials Ratio on High Temperature Composting of Corn Stover. - Guangdong Agricultural Science 44(11): 86-91.

[27] Shi, C. C. (2010): Study on co-metabolism degradation and kinetics of organic pollutants. - Chemical engineering and equipment 7: 164-167.

[28] Wang, W. P., Wang, K. Y., Xue, Z. Y., Zhu, F. X. (2005): Effect of different microbial agents on ammonia volatilization in pig manure compost. - Journal of Applied Ecology 4: 693-697.

[29] Wang, C. F., Ma, S. C., Huang, Y., Liu, L. Y., Fan, H., Deng, Y. (2016): Degradation of rice straw complex strains and microbial community structure succession. - Journal of microbiology 12.

[30] Wang, X. L. (2018): Analysis of the role of organic fertilizer in agricultural production. Rural economy and technology 442(14): 43.

[31] Wei, Z. M., Wang, S. P., Xi, B. D., Zhao, Y., He, L. S., Jiang, Y. H., Liu, H. L. (2007): Changes of humus and organic nitrogen components during composting of domestic waste. - Journal of Environmental Science 27(2): 235-240.

[32] Yan, X., Hou, M. Y., Li, B. Q., Wang, S., Liang, Y. C. (2018): Effects of Microbial Fermentation Bacteria, Biomass Carbon and Mushroom Slag on Sludge Composting. Environmental science research 31(01): 136-142.

[33] Yang, X. Y., Lin, X. W., Dou, S. (2013): Effects of Different Oxygen Conditions on the Humus of Corn Straw in Soil. - Journal of Northeast Forestry University 41(1): 106-108.

[34] Zhang, L., Ma, H., Zhang, H., Xun, L., Chen, G., Wang, L. (2015): Thermomyces lanuginosus is the dominant fungus in maize straw composts. - Bioresource Technology 197: 266-275.

[35] Zhou, Y., Zhu, N. W., Liu, B. W., Zhang, T. P. (2018): Analysis on the effect of microbial agent compounding and strengthening aerobic composting of kitchen waste. Journal of Environmental Engineering 12(01): 294-303.

[36] Zorpas, A. A., Loizidou, M. (2008): Sawdust and natural zeolite as a bulking agent for improving quality of a composting product from anaerobically stabilized sewage sludge. - Bioresour Technol 99(16): 7545-7552.

[37] Zucconi, F., Forte, M., Monac, A. (1981): Evaluating toxicity of immature compost. Biocycle 22(2): 54-57. 